\title{
Improving EFL Learners' Vocabulary Learning Through Short Story Oriented Strategy (SSOS)
}

\author{
Masoumeh Arjmandi \\ Faculty of Humanities, Rasht Branch, Islamic Azad University, Rasht, Iran \\ Farzaneh Aladini \\ Faculty of Humanities, Rasht Branch, Islamic Azad University, Rasht, Iran
}

\begin{abstract}
Vocabulary is the main building block of language learning which acts as the kernel for all language skills. The present study attempts to investigate the effect of applying SSOS on Iranian upper-intermediate EFL learners' vocabulary learning. Lack of English vocabulary knowledge of Iranian learners as EFL learners encounters them with a lot of English using difficulties which influence their language abilities (reading, writing, listening and speaking). To this end, based on convenience non-random sampling selection, 40 upper-intermediate female learners were selected via Quick Placement Test. The participants were assigned to experimental $(n=20)$ and control $(n=20)$ groups. A vocabulary test as a pretest and a posttest were administered to all participants. The data were analyzed through descriptive and inferential statistics using SPSS software. The result of findings indicated that it is helpful to utilize SSOS as a tool to enhance not only learners' conceptual and comprehensible processes in order to discover, guess and grasp the meaning of vocabulary but also to store and internalize them in their minds more successfully.
\end{abstract}

Index Terms - short stories, SSOS, vocabulary learning, VLSs

\section{INTRODUCTION}

As the realm of foreign language teaching has been switching from a mainly teacher-oriented attitude to a learneroriented tendency, an expanded matter has been put on coming to the aid of students to take more engagements for meeting their foreign language learning lacks, wants, and needs. Fan (2015) remarked, over the past decades, a diversity of language teaching methods and approaches have been proposed, practiced, and experienced such as Grammar Translation Method, Audio-Lingual Method, Communicative Language Teaching, Computer Assisted Language Teaching, lexical approach, and so on. While some have gained worldwide recognition, some faded away soon after they were created. In other words, there is a waving of orientation in the methods proposed (Khatib \& Seyedrezaei, 2013). According to Belcher and Hirvela (2000), within the literary devices, the short story is an attractive device to be applied for achieving language teaching and learning goals felicitously. They believe that literature, in light of its authentic input for language learning, has the potential to generate high quality linguistic skills of reading, writing, speaking and listening, quite in line with the principles of Communicative Language Teaching (Belcher \& Hirvela, 2000). With respect to reading, the short story allows learners to efficiently practice speed-reading techniques such as skimming, scanning, and finding the main ideas. In point of fact, not merely do short stories are assisting for language learning aims, in general, they also hasten language learning process, particularly in content-based instruction (Shang, 2006). "The integration of a particular content [e.g., math, science, social studies, literature] with second language teaching aims (Brinton, Snow \& Wesche, 1989, p. 2).

This study attempts to show that English teaching (as a second language) does not merely contain to foster students in the development of linguistic features, but help them learn pragmatic features of language for an effective social interaction and implication. One way to expose students to socio-cultural differences is through the use of literature (i.e., short story, drama, poetry, etc.). Many research studies showed that vocabulary is one of the best indicators of intellectual ability and an accurate predictor of overall verbal intelligence and success at school (Sternberg, 1987). Moreover, a rich vocabulary is a valuable asset and an important attribute in many areas of life, not just in school. Salesmen, politicians, sportscasters, radio personnel, and teachers are only a few professions where a good vocabulary proves to be essential (Soleimani \& Ghazanfari, 2012). Unfortunately, learning vocabulary is something problematic for learners in Iranian context. Iranian learners develop their vocabulary knowledge in classroom, but their learned vocabulary is often forgotten and they cannot utilize them in their daily conversations. For English language learners, an English foreign language environment (like Iran) is "input-poor-context" compared to an English second language atmosphere. Iranian learners of English have less language environmental opportunities to acquire words or non-words, and use them in real world communicative setting.

For this purpose, this study puts an effort to investigate whether applying SSOS method contributes Iranian EFL learners to enrich their vocabulary learning. Therefore, the main problem of Iranian learners is the lack of English natural exposure for learning all aspects of language components through natural inputs and acquisition, so they do not 
achieve a kind of spontaneous use of language vocabulary items, collocations, idioms, etc. Most of Iranian learners have vocabulary learning problems in their English communication situations not only to access but also to recall an appropriate word, and this problem is due to un-internalized forms of words in Iranian learners' minds. However, there is a need for Iranian learners (as EFL learners) to be familiarized on various vocabulary items which are used in various context. Besides, lack of applying a plausible method to teach English vocabulary items is another problem of Iranian learners to form their lexicon, i.e., mental dictionary effectively. An appropriate method can contribute them to have an easy access to English words automatically and effortlessly when they need to use language in reading, writing, listening and speaking. Accordingly, one of the most significant of the current discussion in applying SSOS was to teach English vocabulary skills in the context of the short story affectively and cognitively. According to Martinez (2007), learners enjoy listening to stories; therefore, their motivation and interest for learning and paying attention to new words may increase. In addition, Mohammadnejad (2018, p. 103) said:

....in dealing with short stories, learners have an experience with the powerful real language of personal communication. Through reading short stories, language learners not only can promote gradually their vocabulary size and knowledge but also their communicative and cultural knowledge. Thus, starting to read English short story is a kind of starting to be able to read another longer story.

\section{LITERATURE REVIEW}

Generally, vocabulary is a vital device for communicating, and insufficient of it jeopardizes the literal meaning of utterances in communication. Some researchers made an effort to connect learners' language learning strategies to vocabulary learning (Nemati, 2013). According to Schmitt (2008), mastering vocabulary is the prerequisite of mastering a foreign language. In fact, teaching and learning foreign language vocabulary require different types of techniques, strategies, and methods (Min, 2013; File \& Adams, 2010; Rot, Williams \& Cameron, 2010; Mizumoto \& Takeuchi, 2008). Singleton (1999) believed that it is important to reinforce learners' participation in vocabulary learning (VL) actively. In almost all studies, there was a focus on the pacing of repletion and recall of word lists (Gu, 2003). So, that is why forgetting occurs almost immediately after the first encounter. The main goal of learners' vocabulary learning should include recalling and retrieving simple and compound words, particularly the ability to use them automatically in different situational contexts (Gu, 2003). Among the methods of language teaching, the principle of Grammar Translation Method was based on the foreign language literature through reading and translating the passages (the teachers help the students with new vocabulary). Although with the appearance of structuralism along with behaviorism, and audio-lingual method, literary texts were overlooked, and vocabulary was introduced through dialogue (Collie \& Slater, 1987). This approach toward literature was owing to a lack of experimental research ascertaining the value of literary texts in language classes (Maley, 2001). Moreover, the return of literature for language teaching was strengthened by applied linguistics (Belcher \& Hirvela, 2000). Besides, Hisanoglu (2005) asserted that the use of literature is a technique for teaching social and cultural language domains through integrating reading, writing, listening and speaking.

Some researchers started to study on teaching vocabulary learning strategies (VLSs) as a method of vocabulary training. For example, Noor, Yuosoff, Yasim, and Kamarudin (2016) investigated on the foreign language VLSs in Malaysia, the results of their study indicated that among the factors that contribute to the poor vocabulary student, cannot do vocabulary exercises, and cannot retrieve the new learned vocabulary meaning. They believed that memorizing the words cannot lead to master the English vocabulary. Additionally, Ostovar-Namaghi and Rajaee (2013) studied on the effect of strategy training on vocabulary size in EFL context in Iran (in such context, learners' English vocabulary retention or knowledge is weak in communicative situation). Their study focuses on the strategies of vocabulary training like word formation, antonym and synonym, word definition, and guessing the word meaning through context. Their findings indicated that the instruction of these VLSs may help learners in three ways: firstly, to become better learners, secondly, to become independent and confident learners, and finally, to become more motivated learners. In closing, Anderson (2010) viewed that no VLSs or method of vocabulary teaching is better than another. Learners are different and therefore they use different learning strategies. As Nation cited in Gorgoz and Tican (2020), VLSs are a part of language learning strategies; accordingly, a part of general learning strategies. According to them, VLSs refer to actions that help learners to remember and understand vocabulary elements which lead them to an appropriate vocabulary knowledge for an effective and successful language use.

Regarding the history of short story, $19^{\text {th }}$ century was the birth of short stories (as a literary form) in the magazines which widely attracted people to read more. In addition, all over the 20th Century, there was an extreme use of the short story due to an increase of popular magazines. Writers utilized different literary genres of the short story such as love stories, fantasy and horror stories, crime and mystery stories, and science fiction (Mead, Tilley \& Wong, 2011). Mead, Tilley and Wong (2011) classified Short Stories to twelve modules which are: folklore, myth, legend, fable, parable, folktale, fairy, ghost story, love story, tall tale, trickster tale and urban legend. According to them, jokes, anecdotes, personal recounts and short feature stories in the news may be considered as other varieties of short story. In this regard, considering the importance of innovation in language teaching method, SSOS is introduced in this study as a new language teaching method (using short stories in language classes). Khatib and Seyyedrezaei (2013) viewed that short story oriented strategy is a literature-based method, and the purpose of it is to improve the learners`cultural and 
linguistic knowledge. In fact, the main goal of the short story method of language teaching is to establish meaningful conditions that make learners to learn vocabulary with pleasure which improves not only learners` linguistic competence but also their communicative and pragmatic competence (Khatib and Seyyedrezaei, 2013). As Ellis and Brewster (1991) highly recommended that language teachers should use literary devices like stories as one of the vocabulary learning strategies in order to reinforce the learners' vocabulary knowledge because vocabulary in short stories is presented in a vivid and clear context. Specifically speaking, SSOS involves the learners' minds to get the meaning of the words in context that affects increasingly their retention and remembering. Khatib and Seyyedrezaei (2013) reported following characteristics of a literature-based language teaching method:

- The principal function of language is transactive and interactive communications,

- SSOS is based on humanism and cooperative learning,

- Learners' cultural and linguistic developments are signified,

- Short stories are considered as authentic materials,

- Linguistic, sociolinguistic and communicative competences are emphasized,

- An integration of four language skills (reading, writing, listening, and speaking) is involved.

- The students' native language can be applied to talk about the cultural differences,

- Classroom activities and tasks should be done in a positive atmosphere of group-working or individually,

- Vocabulary should be taught in the situational context of the story,

- The formal structure of grammar should not be ignored,

- An integration of teacher-centered approach along with student-centered approach should be interrelated,

- Fostering learners' minds are led to critical thinkers.

Besides, according to Custodio's and Sutton's (2008) view, literature-based approach like SSOS can open horizons of possibility, allowing students to question, interpret, connect, and explore. It can be assumed that literature allows the students to be creative in their thinking and also gives the learners an opportunity to use the language.

\section{The BENEFICIAL FEATURES OF APPLYING SSOS}

One of the most effective benefits of applying short story - as one of language teaching strategy - is to enhance language learners' writing skills (Afroogh \& Ahmadi, 2019). Khatib and Seyyedrezaei (2013) reported employing short story language teaching as the teaching method can be highly fruitful as it offers the following benefits or advantages:

- Promoting all language skills: SSOS allows instructors to teach the four language skills (reading, writing, speaking, and listening) accordance with learners' language proficiency levels.

- Motivating students: Short stories stimulate the students' eagerness to read them from the beginning to the end because of spending short time. In this regard, Elliott (1990) believed that literature motivates the students to imply language effectively and employ language thoughtfully, emotionally, and communicatively.

- Improving cultural learning: Short stories convey the different cultures of the people lives to the students. Cultural awareness enlightens contrastively students as to the comprehension of people and respect the differences between them. As language learners encounter a new culture and context, they need to be well aware of the cultural differences. Stories encourage language learners as target readers to compare their own culture with the other culture to see whether they find similarities and/or differences between the two cultures in order to avoid of misunderstanding and cultural transmission (Gajdusek, 2005).

- Provoking critical thinking: Different genres of short stories contribute the students to understand their world with different perspective. Therefore, they start thinking critically when they read stories. Young (1996) viewed that short stories not only entertain the students but also taught them to think critically in an easily remembering context.

However, Afroogh and Ahmadi (2019) recommended that foreign language learners should not use the dictionary constantly while reading short story, they should try to guess the meaning of new words. According to them if the number of new words is so high that learners have to refer to the dictionary repeatedly, that text is not suitable for their language level and must be discarded.

\section{METHODS}

\section{A. Research Question}

considering the emphasis and importance placed on learning English vocabulary, the researchers of the present study attempted to investigate a basic strategy of vocabulary training, namely, SSOS to improve the vocabulary knowledge of Iranian upper-intermediate learners, and find an answer for the following question.

Does reading short stories have statistically a significant impact on Iranian upper-intermediate EFL learners' vocabulary learning?

\section{B. Research Participants}

The participants of this study were consisted of 40 learners out of 60 at Iran Language Institute, Kiashahr Branch, Guilan, Iran, who enrolled at upper-intermediate level of English language learning. The age range of them was 
between 18 and 28. All the participants were female monolingual and native speakers of Persian language, they had received prior English instruction in Iran, but in different language institutes and schools. The classes were held three hours of a week (twice a week, 16 sessions in eight weeks). Homogenizing the participants was done through Oxford Quick Placement Test (QPT) which was administered before a pretest. Forty learners (the main participants) with the score of $1 \mathrm{SD}$ above and below the mean (1SD \pm mean) were selected based on the convenience way of sampling selection in order to participate in this research. Half of participants were assigned as the experimental group and received vocabulary teaching based on SSBOS as training program (reading two short stories for vocabulary learning during a language learning course). The other 20 learners (classified as the control group) received traditional method of teaching vocabulary. The vocabulary items were considered the same for both groups (the control group and the experimental group). Also, the classes were held three hours of a week (twice a week, 16 sessions within eight weeks).

\section{Materials and Procedures}

The materials used for conducting the research were instructional and testing materials. Instructional materials were consisted of a two-month SSOS program through reading two short stories offered to the experimental group were "The Christmas Present" and "The Last Leaf", both short stories consisted of three short parts and were written by O Henry (1910). For achieving the vocabulary teaching and learning goals, three worksheets were distributed to experimental learners at the first session of each story (in the form of three tasks), and they were asked to complete carefully. The treatment program was based on Erkaya's (2005) three major SSOS activities, namely, pre-reading, while-reading and post-reading activities. But, the control group received no formal SSOS instruction rather traditional way of teaching vocabulary through reading the stories, paraphrasing, summarizing the stories and telling the word meanings. Whereas, the procedures and activities for teaching vocabulary in experimental class was different which are listed below:

- Teacher employed three reading activities (pre-reading, while-reading and post-reading),

- Learners worked in groups of three or four,

- Teacher distributed the three worksheets and explained how to complete them (tasks 1, 2 \& 3),

- Learners brainstormed in groups and complete the worksheets,

- Teacher asked guiding questions (to elicit the answer), asked students to describe the event where the event happened,

- Learners shared their responses with the whole class,

- Teacher assigned roles for learners and gave them time to do the role play,

- Teacher asked learners to discuss about the characters and events of the stories.

Besides, the testing materials of this study included three tests which were administered to all participants. The first test was QPT for determining the participants' English proficiency level. The second one was "the pretest" which was a standardized Vocabulary Test (VT) developed by McCarty and O'Dell (for upper-intermediate learners) from Cambridge University (2002). It consisted of four parts with 40 vocabulary items for diagnosing the participants' potential problem of English knowledge of vocabulary (their weaknesses and strengths). The third one was "the posttest" which was developed based on McCarty's and O'Dell's (2002) patterns and scales. The posttest consisted of five parts with 30 vocabulary items based on the content and the words of the two aforementioned short stories. The posttest assessed learners' knowledge of words recognitions (nouns, verbs, adjectives / adverbs).

\section{RESULTS}

The results are presented in two parts: The first part deals with pretest (pre-training), and the second part presents posttest (post-training). As it was shown in Tables 1 and 2, it was revealed non-significant differences between the results obtained from two group scores in pretest before SSOS training program. The subjects were nearly at similar level in terms of their English vocabulary skill.

TABLE 1

DESCRIPTIVE STATISTICS OF BOTH GROUPS For THE PRETEST SCORES

\begin{tabular}{|c|c|c|c|c|}
\hline Groups & $\mathbf{N}$ & Mean & Std. Deviation & Variance \\
\hline Exp. & 20 & 14.80 & 2.28 & 5.19 \\
\hline Ctrl. & 20 & 14.05 & 2.35 & 5.52 \\
\hline
\end{tabular}

As demonstrated in Table 1, the values of means and standard deviation in the pretest performance for both groups were somehow small and identical. The results of the pretest showed that the mean of the control group $\left(M_{\text {control group }}=\right.$ $14.05)$ and the mean of the experimental group $\left(M_{\text {experimental group }}=14.80\right)$ did not differ statistically. In other words, the mean difference was not statistically significant for the pretest scores of VT before initiating the specific treatments for the experimental group. Before accomplishing the analysis, the main supposition of independent samples $t$-test, namely, normality of the distributions was examined through running Levene's test (Table 2). 
TABLE 2

TEST OF HOMOGENEITY OF VARIANCES FoR THE PRETEST

\begin{tabular}{ccccc}
\hline Levene Statistic / F & df1 & df2 & Sig. \\
\hline .395 & 1 & 38 & .618 & \\
\hline
\end{tabular}

According to Table 4.4, the Levene's test was not significant for the pretest scores: $F_{\text {pretest }}(1,38)=.395, p=.618$ at the .05 alpha level. Thus, the assumption of homogeneity of variance was met for the sample. Also, Table 3 displays the results of the independent samples $t$-test for the pretest scores. Results indicated that there was no statistically significant difference in learners' vocabulary ability on the pretest scores across the groups $(t=.82 \mathrm{with} \mathrm{df}=38, p$ vocabulary test $.197 \geq .05)$.

TABLE 3

INFERENTIAL STATISTICS OF THE INDEPENDENT SAMPLES T-TEST FOR THE PRETEST SCORES

\begin{tabular}{|c|c|c|c|c|c|c|c|}
\hline \multicolumn{8}{|c|}{$t$-test for Equality of Means } \\
\hline \multicolumn{8}{|c|}{$\begin{array}{c}95 \% \text { Confidence } \\
\text { Interval of the } \\
\text { Difference } \\
\end{array}$} \\
\hline Groups & $\mathbf{N}$ & df. & SED & $\mathbf{t}$ & sig.(two-tailed) & Lower & Upper \\
\hline Exp. \& Ctrl. & 40 & 38 & .91 & .82 & .197 & 11.38 & 12.82 \\
\hline
\end{tabular}

The significance value of the probability (sig. two-tailed) in the $t$-test table was higher than alpha (.05) for the pretest scores of vocabulary learning. As a result, the non-significant $p$ value revealed that the population means on test of vocabulary were similar at the beginning of the study. Also before accomplishing the analysis, the main supposition of independent samples $t$-test, namely, normality of the distributions was examined through running Levene's test which was not significant for the pretest scores: $F_{\text {pretest }}(1,38)=.395, p=.618$ - at the .05 alpha level. Thus, the assumption of homogeneity of variance was met for the sample. The descriptive statistics for the posttest data are presented in Table 4:

TABLE 4

DESCRIPTIVE STATISTICS OF Both GROUPS For THE POSTTEST SCORES

\begin{tabular}{|c|c|c|c|c|}
\hline Groups & $\mathbf{N}$ & Mean & Std. Deviation & Variance \\
\hline Exp. & 20 & 16.70 & 1.93 & 3.72 \\
\hline Ctrl. & 20 & 14.86 & 2.19 & 4.79 \\
\hline
\end{tabular}

The results of the descriptive statistics for the posttest showed that the mean of the control group $\left(M_{\text {control group }}=\right.$ 14.86), and the mean of the experimental group $\left(M_{\text {experimental group }}=16.70\right)$ differed significantly. In addition, the result of Levene's test (homogeneity of variances) for the posttest scores was also not significant: $F_{\text {posttest }}(1,38)=2.222, p$ $=.121-$ at the .05 alpha level. Thus, the assumption of homogeneity of variance was not violated for the posttest scores, too. As shown in Table 5 .

TABLE 5

HOMOGENEITY OF VARIANCES FoR THE POSTTEST

\begin{tabular}{|c|c|c|c|}
\hline Levene Statistic / F & df1 & df2 & Sig. \\
\hline 2.222 & 1 & 38 & .121 \\
\hline
\end{tabular}

Table 6 displays the results of inferential statistics of the independent samples t-test for the posttest means.

TABLE 6

INFERENTIAL STATISTICS OF TEH INDEPENDENT SAMPLES T-TEST FOR THE POSTTEST MEANS

\begin{tabular}{|c|c|c|c|c|c|c|c|}
\hline \multicolumn{8}{|c|}{$t$-test for Equality of Means } \\
\hline \multicolumn{8}{|c|}{$\begin{array}{c}95 \% \text { Confidence } \\
\text { Interval of the } \\
\text { Difference }\end{array}$} \\
\hline Groups & $\mathbf{N}$ & df. & SED & $\mathbf{t}$ & sig.(two-tailed) & Lower & Upper \\
\hline Exp. \& Ctrl. & 40 & 38 & 0.33 & 5.57 & .000 & 13.81 & 14.57 \\
\hline
\end{tabular}

According to Table 6, the hypothesis that average assessment scores of the vocabulary recalling ability (the posttest) were equal across the two groups was rejected $(\mathrm{t}=5.57 \mathrm{df}=38$, Sig. $=.000 \leq .05)$. The significance value of the probability (Sig.) in $t$-test table was less than alpha .05. Figure 1 illustrates mean plots for the results of the posttest of the learners' VT. 


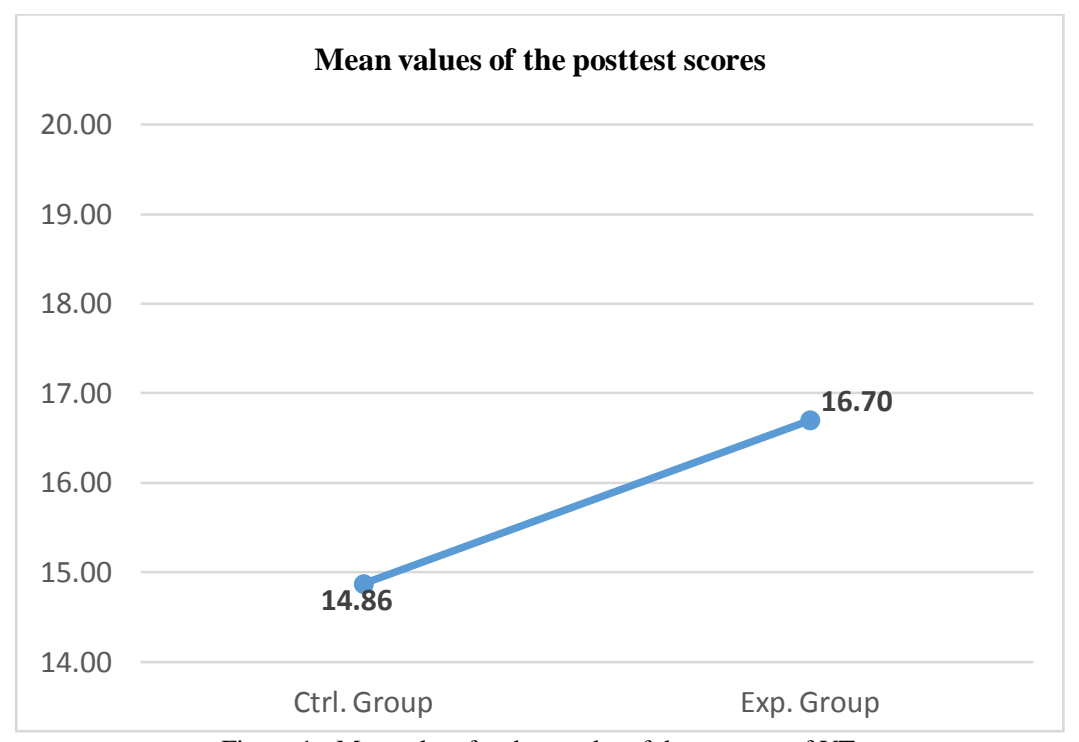

Figure 1: Mean plots for the results of the posttest of VT

Likewise, according to Mackey and Gass (2005, p. 282), the most common measurement that can be used after a $t$ test is eta squared (expressed as $\eta^{2}$ ), which goes beyond the fact that there is a significant difference and gives an indication of how much of the variability is due to independent variable (instruction type).

The formula for eta squared is as follows:

$$
\begin{aligned}
& \text { eta squared }\left(\eta^{2}\right)=\text { - } t^{2}+\left(\mathrm{N}_{1}+\mathrm{N}_{2}-2\right) \\
& \eta^{2}(\text { for } t \text {-test })=\frac{5.57^{2}}{-\cdot-.----} \\
& 31.12 \\
& =--------0.44
\end{aligned}
$$

eta squared $\left(\eta^{2}\right)=0.44$

It means that $44 \%$ of the variability in two groups' scores can be accounted by other effects and $56 \%$ can be accounted by instruction type because the magnitude of differences in the means is large. Moreover, after confirming that the both groups differed in some way, in order to investigate the extent of the students' progression within groups, two paired samples $t$-tests were also run (one for the control group and one for the experimental group), which showed

\begin{tabular}{|c|c|c|c|c|c|c|}
\hline \multicolumn{7}{|c|}{ Paired Samples Statistics } \\
\hline Groups & & & Mean & $\mathbf{N}$ & $\begin{array}{c}\text { Std. } \\
\text { Deviation }\end{array}$ & Std. Error Mean \\
\hline \multirow[t]{2}{*}{ Control group } & Pair 1 & Pretest scores & 14.05 & 20 & 2.35 & .655 \\
\hline & & Posttest scores & 14.86 & 20 & 2.19 & .684 \\
\hline \multirow[t]{2}{*}{ Experimental group } & Pair 1 & Pretest scores & 14.80 & 20 & 2.28 & .560 \\
\hline & & Posttest scores & 16.70 & 20 & 1.93 & .543 \\
\hline
\end{tabular}
the subjects' progress in the pretest and the posttest (see Table 7).

TABLE 7

Paired SAmples T-Test For The PRetest And The PostTest Means Of Both Groups

As shown in Table 7, the mean scores of the control group improved from (14.05) in the pretest to (14.86) in the posttest. With respect to the performance of the participants in the experimental group, the mean score increased from (14.80) in the pretest to (16.70) in the posttest. According to Tables 5, both groups progressed in the posttest. Based on the results of paired samples $t$-test, this improvement was statistically significant simply for the experimental group ( $p \leq$ 0.05). In other words, the two groups made a substantially progress in the posttest of vocabulary learning. However, this progress was not statistically significant for the control group ( $p \geq 0.05)$. These results also rejected the null hypothesis.

\section{DISCUSSION}


One of the problematic aspects of EFL teaching / learning, namely vocabulary teaching through SSOS method has been elaborated in the present research. It investigated a direct relationship between SSOS and the learners' improvement vocabulary skills. Mart (2012) argued that vocabulary is an indispensable part of a language and teaching English vocabulary is an important field in language teaching. This research found out applying SSOS method are increasingly related to two main factors: learners' knowledge of language and teachers' knowledge of language and teaching methodology. Because, from one side, teachers as conductors, helpers and facilitators can pave the pathway when they are competent and knowledgeable, and the other side, the collaboration of learners regarding their knowledge and abilities facilitate learning and teaching processes considerably. Hence, utilizing SSOS as scaffolding tool creates easily a bridge between teachers' language teaching method and learners' language learning approaches in a collaborative way. Similarly, the processes of achieving language teaching and learning goals will be facilitated cognitively and emotionally. Foremost, one of the most popular concepts advanced by Vygotsky (1978) was the notion of a Zone of Proximal Development (ZPD) in every learner. The central core of Vygotsky's theory is "scaffolding", he believed that there is a difference between what a child can do individually in isolation and what s/he can perform socially across context (mediation and intervention to the future progresses). This study found out the instruction of English vocabulary via SSOS plays significant role as an intermediator which directs Iranian learners (as EFL learners) from their actual level to their potential level of English vocabulary improvement toward a dynamic level of vocabulary knowledge in order to apply their knowledge through their communication appropriately and felicitously, but this level requires to build scaffolding (like SSOS method) in order to facilitate the process of language teaching and learning. Besides, this research found that applying SSOS method in EFL classroom is a kind of dynamic method towards language teaching and learning, particularly, it is a teacher-learner-centered approach comparing to traditional passive one. In SSOS method, teacher and learners come to an agreement to choose the genre (type) of short story based on the learners' interest, to select classroom activities (role-play, drama, etc.) based on learners' needs and wants as well as the goals of teaching and learning. SSOS method can help learners use the foreign language to express their thoughts in terms of situational context. This method can simultaneously increase learners' knowledge linguistically and contextually as well as enhance their critical thinking ability.

To elaborate on the pedagogical implications of this study, it can be argued that because the results of the present study showed short story oriented strategy can have a significant effect on the learners' vocabulary learning, some language teaching and learning activities can be designed. Utilizing various real world activities and practices through authentic materials like short stories prepare EFL learners to become more able and independent to use English effectively in their communications. Short story oriented strategy enhances the presupposition attitude in learners to think, activates learners' schemata for processing the vocabulary items cognitively, and to express their views critically. Specifically speaking, in Iran, curricula, syllabuses and assessment models of English teaching need pedagogically to be developed or designed, because, pedagogical tactic maximizes the learners' attentions towards vocabulary learning as one of English skill for their future professionals such as engineering, nursing, medical, banking, and so on. Foremost, pedagogically, vocabulary teaching needs an appropriate method which should be adopted, appropriate materials which should be developed and appropriate practices, tasks and activities which should be designed based on EFL learners' needs, goals and interest to engage their cognitive and productive abilities with a high conceptual and habitual language learning. Hence, it will be very useful to pay more attention to teaching vocabulary via short story oriented strategy in Iranian English education. Last but not least, this study attempted to highlight the role of English teachers in "scaffolding" for manageable vocabulary teaching by applying an appropriate method (like SSOS) in order to provide vocabulary learning opportunities for learners.

\section{CONCLUSION AND SUGGESTIONS}

The purpose of this study was to examine the impact of using SSOS for improving learners vocabulary learning. The results obtained through SSOS for improving upper-intermediate learners' vocabulary learning in this study demonstrated that learners' receiving 16 sessions of SSOS activities and tasks attained higher scores than those who did not, over their vocabulary test (posttest). It was proved that teaching vocabulary through reading short story to the experimental group was more successful than to the control group with traditional way of vocabulary training. It should be repeated that based on the findings and comparing the pretest and posttest scores in both experimental and control groups, SSOS contributed to give the classroom a more meaningful and cohesive environment, and as an influential and beneficial skill in learners' attention, perception and comprehension of language learning. It can improve Iranian EFL learners' language fluency and accuracy. The atmosphere of the experimental group's class was more fun, creative and positive and the students' roles in vocabulary learning changed from passive into active ones who always tried to participate in SSOS tasks. Consequently, it is helpful to utilize SSOS as a tool to enhance not only learners' vocabulary skill but also their language development which engages learners' cognitive process to internalize learning materials. Employing SSOS embarks learners' productive abilities (speaking and writing) as well as their receptive abilities (listening and reading) through acquiring a sufficient vocabulary (a necessary component of language learning).

In line with the result and conclusions of this research, the researchers would like to propose some suggestions for further research. The data gathering of the present study was based on the pretest and the posttest, the future research can utilize other instruments such as interviews, and questionnaires to determine teachers' and learners' perceptions on 
vocabulary learning and vocabulary teaching method types. Another suggestion for doing more research is to conduct such studies for improving students' knowledge of the socio-cultural, cross-cultural or cultural differences between English and Persian.

\section{ACKNOWLEDGMENTS}

Thank you for all people who have helped the researchers in finishing this study. My appreciation goes as well to the manager and the learners of Iran Language Institute, Kiashahr Branch for their kind contribution in participating in this study.

\section{REFERENCES}

[1] Afroogh, M. R., \& Ahmadi, S. M. (2019). Does Short Story Reading have any effect on English Language Learning? Annals of Language and Literature, 3(4), 33-37.

[2] Anderson, J. (2010). Cognitive psychology and its implications. San Francisco: Freeman.

[3] Belcher, D., \& Hirvela, A. (2000). Literature and L2 composition: Revisiting the debate. Journal of Second Language Writing, 9(1), 21-39.

[4] Brinton, D., Snow, M., \& Wesche, M. (1989). Content-based second language instruction. New York: Newbury House.

[5] Collie, J., \& Slater, S. (1991). Literature in the language classroom ( $5^{\text {th }}$ ed.). Glasgow: Cambridge University Press.

[6] Elliot, R. (1990). Encouraging reader-response to literature in ESL situations. ELT Journal, 44(3), 19- 198.

[7] Erkaya, O. (2005). Benefits of using short stories in the EFL context. Asian EFL Journal, 8, 1-13.

[8] Fan, N. (2015). A study of vocabulary knowledge and vocabulary learning strategies of Chinese EFL learners. Ph.D. dissertation, Macquarie University. Retrieved from: https://www.resesrchonline.mq.edu.au/vital/access/services/Download/mq.../SOURCE1 . (26. Mar. 2020).

[9] File, K. A. \& Adams, R. (2010). Should vocabulary instruction be integrated or isolated? TESOL Quarterly, 44(2), $222-249$.

[10] Gajdusek, L. (1988). Toward wider use of literature in ESL: Why and how. TESOL Quarterly, 22(2), 227-257.

[11] Gorgoz, S., \& Tican, C. (2020). Investigation of middle school students' self-Regulation skills and vocabulary learning strategies in foreign language. International Journal of Educational Methodology, 6(1), 25-42.

[12] Gu, Y. (2002). Gender, academic major, and vocabulary learning strategies of Chinese EFL learners. RELC Journal, 33(1), 3554.

[13] Gu, Y. (2003). Vocabulary learning in a second language: person, task, context and strategies. TESL-EJ, 7(2), 1-25.

[14] Hismanoglu, M. (2005). Teaching English through literature. Journal of Language and Linguistic Studies, 1(1), 53-66.

[15] Khatib, M., \& Seyedrezaei, S. H. (2013). Short story based language teaching (SSBLT): A literature-based language teaching method. International Journal of Basic Sciences and Applied Research, 2(2), 155-159.

[16] Lessard-Clouston, M. (1996). ESL vocabulary learning in a TOEFL preparation class: A case study. Canadian Modern Language Review, 53(1), 97-119.

[17] Maley, A. (2001). Literature in the language classroom. In R. Carter, \& D. Nunan, (eds.), The Cambridge guide to teaching English to speakers of other languages. Cambridge University Press. 180-185

[18] Martinez, B. (2007). A story-based approach to teaching English: A classroom experience. Encuentro, 17 (1), 52-56.

[19] Mart, C. T. (2012). Guessing the meaning of words from context: why and how. International Journal of Applied linguistics and English Literature, 1(6), 177-181.

[20] Mead, S., Tilley, A., \& Wong, H. (2007). Networking: Using short stories in the English classroom. Retrieved from: www.edb.govhk/../NETworking\%20short\%20stories (26. Mar. 2020).

[21] Min, Y. (2013). Vocabulary acquisition: Practical strategies for ESL students. Journal of International Students, 3(1), 64-69.

[22] Mizumoto, A. \& Takeuchi, O. (2008). Exploring the driving forces behind TOEIC scores: Focusing on vocabulary learning strategies, motivation, and study time. JACET Journal, 46. 17-32.

[23] Mohammadnejad, L. (2018). The effect of reading short stories on learning English collocation among pre-intermediate EFL learners. Journal of Sociological Research, 9(1), 102-116.

[24] Murdoch, G. (2002). Exploiting well-known short stories for language skills development. IATEFL LCS SIG Newsletter, 23, 917.

[25] Nemati, A. (2013). Vocabulary learning strategies: A short way to long term retention. Linguistics and Literature Studies, 1(1), 8- 14.

[26] Nemati, A. (2013). Increasing depth of vocabulary: A hidden aspect of vocabulary knowledge. International Journal of Language Learning and Applied Linguistics World (IJLLALW), 4(3), 313-322.

[27] Noor, Z., Yuosoff, N., Yasim, I., \&. Kamarudin, M. (2016). Foreign language vocabulary learning strategies in Malaysia. Creative Education, 7(3), 428-434.

[28] Ostovar-Namaghi, S., \& Rajaee, M. (2013). Effect of strategy training on vocabulary in EFL contexts. Retrieved from: www.files.eric.ed.gov/fulltext/ED543392.pdf (28. Mar. 2020).

[29] Rott, S., Williams, J., \& Cameron, R. (2002). The effect of multiple-choice L1 glosses and input-output cycles on lexical acquisition and retention. Language Teaching Research, 6, 183-222.

[30] Schmitt, N. (2010). An introduction to applied linguistics. London: Hodder Education Publishers.

[31] Shang, H. (2006). Content-based instruction in the EFL literature curriculum. The Internet TESL Journal, 12(11).

[32] Soleimani, M. \& Ghazanfari, M. (2012). Incidental vocabulary acquisition: The effect of reading and listening to stories on vocabulary acquisition of Iranian EFL students. Retrieved from: www.ganj.irandoc.ac.ir/articles/donlowad_sparse/511729 (17. Apr. 2020).

[33] Vygotsky, L. S. (1978). Mind in society: development of higher psychological processes. Cambridge: MA, Harvard University Press. 
[34] Young, A. (1996) Introducing Critical Thinking at the College Level with Children's Stories, College Teaching, 44(3), 90-93. doi: 10.1080/87567555.1996.9925558
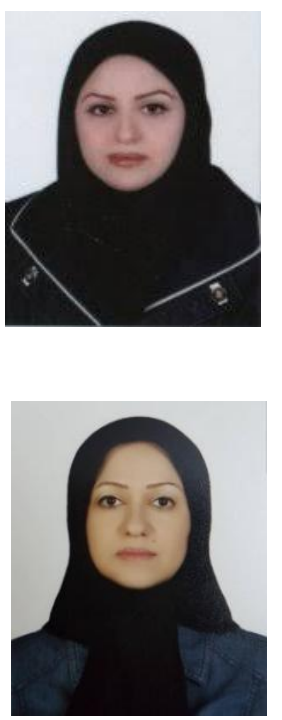

Masoumeh Arjmandi, Ph.D., was born in Rasht, Guilan, Iran, on March, 1975. She is an assistant professor of linguistics at Department of English Language, Linguistics and Literature, Faculty of Humanities, Rasht Branch, Islamic Azad University, Rasht, Iran. She received her M.A. in Linguistics from Allameh Tabataba'i University, Tehran in 2003, and her Ph.D. in Linguistics from Tarbiat Modares University, Tehran in 2010. She is the chief founder of linguistics course at her university. She is the author of two books and numerous articles. She exercises specifically discourse analysis, CDA and phonetics through applied linguistics including translation and teaching (arjmandi@iaurasht.ac.ir).

Farzaneh Aladini is a lecturer at Department of English Language, Linguistics and Literature, Faculty of Humanities, Rasht Branch, Islamic Azad University, Rasht, Iran. She received her B.A. in English literature from Shiraz University, Shiraz, Iran in 1990, and her M.A. in English Literature from Allameh Tabataba'i University, Tehran in 1996. She is the author of three books. Her research interests include English literature, composing haiku, teaching poetry and short story in EFL/ESL classes. (aladini @iaurasht.ac.ir) 